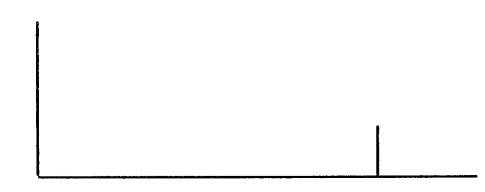

Rev. Latinoam. Psicopat. Fund., VIII, 4, 794-811

\title{
As doenças mentais nos climas tropicais*
}

Juliano Moreira

Afrânio Peixoto

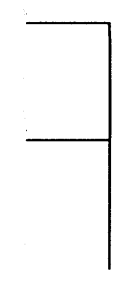

\footnotetext{
As questões de geografia médica perderam muito da importância atribuída a elas quando se acreditava que cada região da terra, conforme sua latitude e longitude, tinha uma característica mórbida, assim como determinada característica etnográfica, zoológica ou fitográfica etc.

Essas concepções eram facilitadas por uma noção demasiadamente ampla, e por isso mesmo mal delimitada, das zonas climáticas. Sob o império de tais idéias teóricas e antes de se

* Comunicação apresentada no XV Congresso Internacional de Medicina, Lisboa, 1906. Originalmente publicado em francês: Les maladies mentales dans les climats tropicaux. Archivos Brasileiros de Psychiatria, Neurologia e Sciencias Affins, ano II, n. 3, p. 22241, setembro de 1906. Tradução para o português de Monica Seincman.

Revisão técnica e notas de Ana Maria G R. Oda. As referências bibliográficas citadas no texto (numeradas no original) tiveram sua forma de apresentação atualizada $\mathrm{e}$ padronizada (autor, ano); a lista de referências bibliográficas, que no artigo original apresenta muitos itens incompletos, foi provida das informações possíveis de obter em fontes primárias.
} 


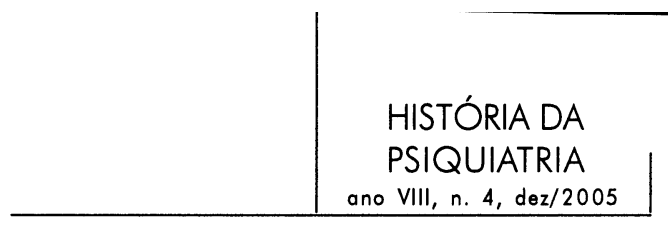

haverem realizado pesquisas realmente científicas em cada região, atribuía-se a cada clima uma certa patologia, clara, precisa, e expressamente separada de todas as outras por delimitações exatas.

Tais preconceitos patológicos resultavam, em grande parte, da falta de uma noção etiológica positiva, em conseqüência dos conhecimentos insuficientes da época, e da ausência de estudo clínico comparado que as conclusões apressadas dos médicos viajantes não permitiam.

A etiologia mais esclarecida de nosso tempo e a higiene mais bem preparada de nossos dias vieram dissipar crenças mal fundadas e reduzir a questão a seus verdadeiros termos.

Reconheceu-se o quase cosmopolitismo de todas as doenças, ou pelo menos sua fácil aclimatação, já que concorrem, em qualquer que seja a região da terra, certas condições necessárias ao seu desenvolvimento. Quase não há doença que não tenha sido observada tanto no Norte quanto no Sul, tanto no Oeste quanto no Leste. Não há região no mundo que particularmente possua uma única doença, e não há doença que não possa, mesmo em seus domicílios eventuais, ser exterminada pelos meios higiênicos de nosso tempo.

Como exemplo da veracidade da primeira destas afirmações, citaremos a cólera e a peste. A febre amarela e a malária provam a veracidade da segunda.

O que há, quando existe, são variações clínicas, resultante complexa da intensidade mórbida, da resistência individual, da defesa higiênica, do combate terapêutico: conjunto de condições em que os coeficientes climáticos podem bem entrar em parte, mas para as quais eles jamais contribuem nem mediata nem diretamente. Esta é a observação geral, que não poderia infirmar fatos particulares, ainda obscuros e partindo de interpretação variada, que se lhe poderia opor.

Para empreender frutiferamente nosso estudo, é necessário ter noções exatas sobre os climas denominados tropicais. Jules Rochard teve o cuidado de nos prevenir que qualquer classificação dos climas é arbitrária. A sua não escapa a esta crítica, tendo sido, no entanto, adotada pela maioria dos higienistas. A base térmica adotada é passível de sérias objeções. É sempre verdade que as médias térmicas são como roupas prontas: nenhuma tem a medida certa. Na realidade, sabemos, quase não há climas de zonas nem climas de regiões; há, acima de tudo, climas de localidades.

Entretanto, por ser cômodo ligar os climas de localidade a qualquer uma das grandes divisões que representam os climas de zona, cujas características são convencionalmente bastante bem definidas e conhecidas, declaramos que utilizamos para nossas comparações os documentos relativos aos países situados entre as isotermas de $+20^{\circ}$ ao Norte e $+20^{\circ}$ ao Sul. 


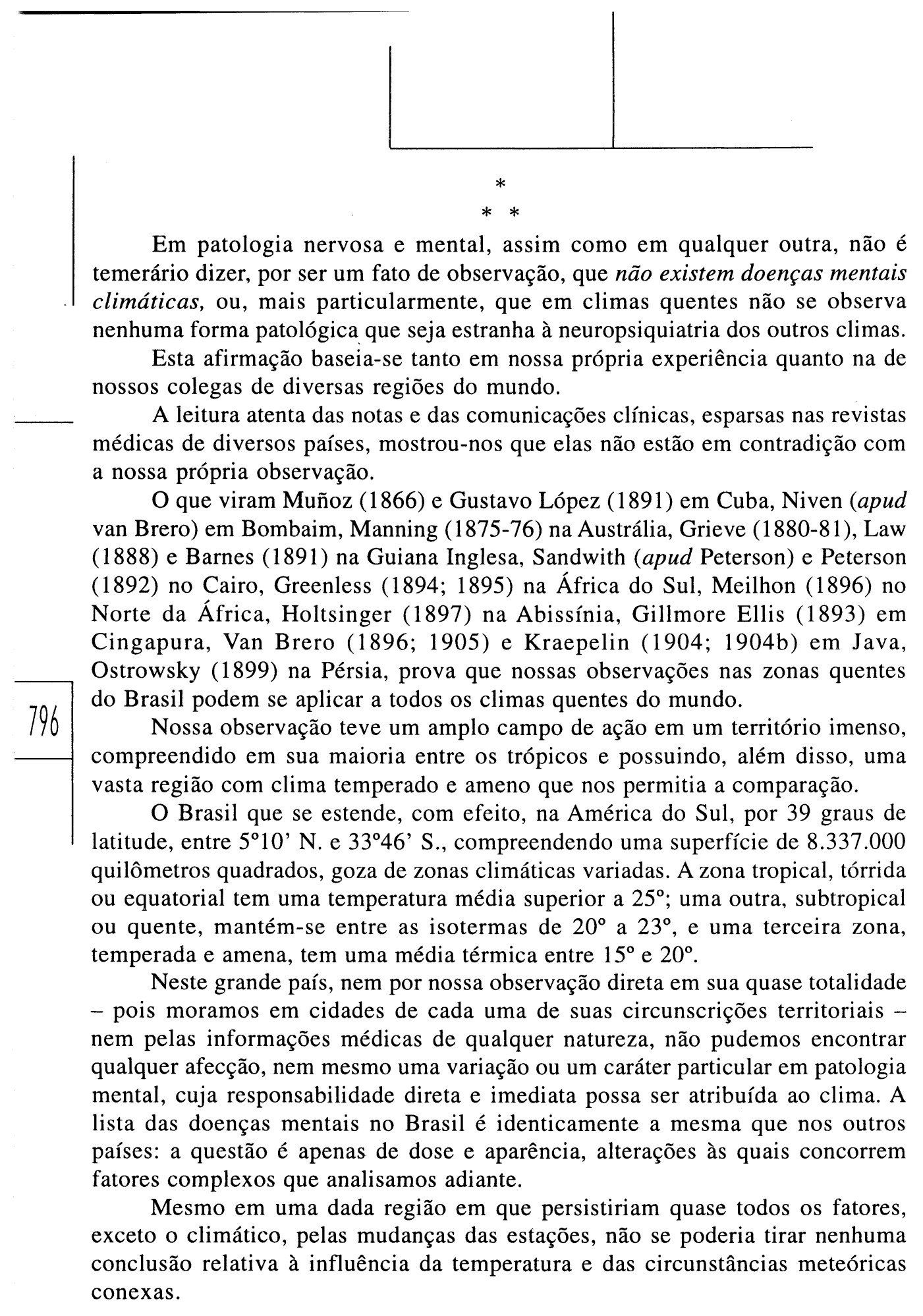




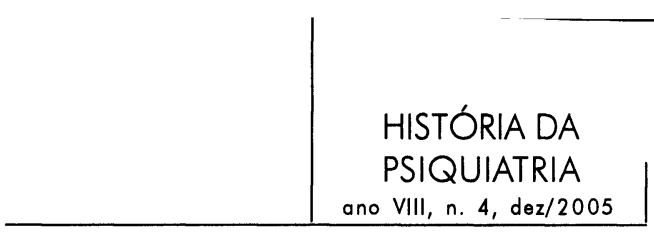

Um gráfico anexo a este estudo ${ }^{1}$ mostra, com efeito, as curvas das máximas, das médias e das mínimas térmicas mensais no Rio de Janeiro durante dez anos, projetadas sobre a linha da proporção dos casos de loucura sobrevindos nesta cidade e observados no Hospital Nacional de Alienados: é impossível chegar a uma dedução clara quanto à influência da temperatura etc. sobre as psicoses constatadas, visto os dados do problema que variam de um ano para outro. É verdade que, no mais das vezes, a admissão no hospital não coincide com o início da doença, mas coincide, pelo menos na maioria dos casos, com as exacerbações que justificam a urgência da internação. A única dedução permitida é que, se realmente o clima, pelo menos em seus componentes principais como temperatura, estado higrométrico etc., influi nas determinações mórbidas mentais, esta influência é contrabalançada, mascarada e anulada por uma complexidade obscura de outras condições, de maneira que é impossível atribuir-lhe uma importância ou um valor qualquer.

Esquirol (1838, p. 24) pensava que os climas quentes produziam menos loucos do que os temperados, sujeitos a grandes variações atmosféricas, e que havia menos alienados na Grécia, na Turquia, nas Índias do que no Norte da Europa. Mas é também nessas regiões onde estão situados os países em que a assistência é mais desenvolvida. No entanto, nos países frios em que a civilização é atrasada e em que ainda não existem os inconvenientes da vida intensiva, como a Groenlândia, a Islândia, a Sibéria etc., não se tem notícia de que a loucura seja mais freqüente do que nas zonas quentes pouco civilizadas. Em contrapartida, no que diz respeito ao Brasil, a loucura se torna cada dia mais freqüente em suas zonas quentes, proporcionalmente aos progressos da civilização que, ao lado de suas grandes vantagens, acarreta o aumento dos vícios e das doenças crescendo, como parasitas, à sua sombra.

Nos climas quentes, qual é o valor das influências meteorológicas sobre os alienados? Esquirol (1838, p. 26) dizia que, nos equinócios, os alienados ficavam mais falantes. Conforme Guislain (1880), haveria algumas relações, difíceis de precisar, entre a exacerbação e a remissão da loucura, por um lado, e os tempos muito úmidos, os ventos, as tempestades e a eletricidade atmosférica, por outro.

Lombroso (1867) observara que dois ou três dias antes das grandes variações atmosféricas, certos alienados, os estúpidos, os idiotas, os dementes e principalmente os epilépticos, parecendo-se nisso a muitos dos animais, ficavam muito agitados.

Estudamos a questão comparando o levantamento dos ataques dos epilépticos do Hospital Nacional de Alienados com os dados meteorológicos do

1. O referido gráfico não foi encontrado em nossa cópia do original (nota da revisora - N. da R.). 


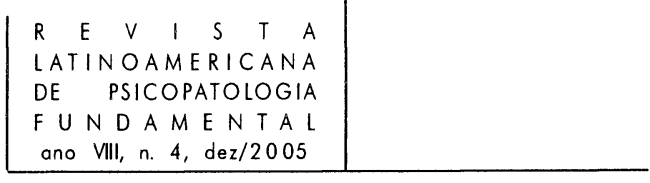

Observatório do Rio e da seção meteorológica da Marinha. Os fatores estudados foram a temperatura, o estado do céu (nuvens), a chuva, o estado higrométrico, a força e a direção do vento, a pressão atmosférica, as tempestades.

Além disso, pesquisamos a influência das fases lunares.

Deste estudo minucioso, acreditamos poder concluir que, pelo menos quanto ao clima, não existem relações entre os fenômenos atmosféricos e o aparecimento dos ataques convulsivos nos epilépticos.

Nos países quentes, assim como nos países frios, ao observar com atenção e, em particular, os casos clínicos, observa-se que há grandes diferenças individuais e que, com frequiência, o modo de reagir de um doente não é semelhante em duas ocasiões aparentemente idênticas.

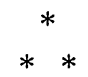

A comparação de algumas cifras de nossas estatísticas com as européias, assinalando as variações e as diferenças destes números para cada doença mental, permitir-nos-á indicar as causas prováveis do fato indicado.

\section{Idiotia}

A idiotia apresenta em nossas zonas climatéricas com médias térmicas mais elevadas, assim como naquelas com médias menos elevadas, todas as formas descritas nos países frios. Comparando o que observamos no Brasil com o que vimos nos hospitais europeus, nada temos de particular a assinalar em nosso país. Nossa proporção inferior em relação a ela, relativamente aos outros países, é devida exclusivamente ao fato de que nossos hospitais apenas recebem um número mínimo de casos de idiotia; os doentes mais inofensivos permanecem quase sempre confiados aos cuidados de suas famílias.

\section{Imbecilidade e debilidade mental}

Quanto à imbecilidade e à debilidade mental, podemos igualmente afirmar que elas não apresentam sintomatologicamente nada diferente do que se observa nos países frios. Sua grande freqüência em alguns distritos rurais não poderia ser atribuída ao clima, porque esta frequiência existe em localidades com médias térmicas muito temperadas. Não acreditamos, aliás, que as duas modalidades de disfrenias degenerativas sejam mais freqüentes no Brasil do que na Irlanda e na Rússia, por exemplo. As causas de sua freqüência; em nosso país, são as mesmas que em outros países. Pedimos observar, no entanto, que uma das mais graves, 


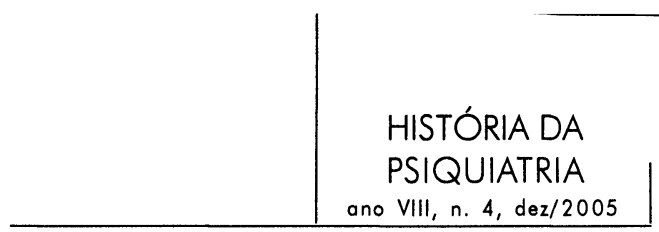

nos Estados da Bahia, Pernambuco, Ceará, São Paulo, Rio de Janeiro, Minas e Espírito Santo, é o número extraordinário de doentes de ancilostomíase nos distritos rurais. Os descendentes desses doentes são freqüentemente imbecis ou débeis mentais, sem que nenhuma outra causa pareça ter concorrido para este resultado.

O alcoolismo, a sífilis e o impaludismo são os outros fatores da freqüência da imbecilidade, assim como da idiotia, em nossas zonas tropicais.

\section{Neurastenia}

Os números que figuram em nossas estatísticas são exíguos por dois motivos: o primeiro é que o lugar de nossa observação é um Hospital de Alienados, em que os doentes são sempre levados pela polícia ou por seus parentes, e a internação dos neurastênicos, em geral, não é urgente. O segundo motivo é que se a neurastenia tem como desenvolvimento, como acontece com bastante freqüência, uma perturbação mental mais grave ou mais notável, o caso em questão figura sob esta última rubrica. É preciso considerar, além disso, que duas das principais condições causais da neurastenia estão ainda em estado rudimentar no Brasil, mesmo em sua capital, a saber: a estafa por excesso de trabalho ou outro [excesso] e o esgotamento venéreo, principalmente por perversões sexuais. Nossas condições de civilização ainda não nos causaram estes tristes efeitos, que esgotam os povos com uma vida mais intensa. Talvez venha daí a raridade dos neurastênicos em nossos hospitais. Na clínica particular, no entanto, já são freqüentes e, se um número maior não é observado, é porque cruzam com bastante frequiência o oceano para irem consultar os grandes especialistas europeus, ou aumentar o número dos freqüentadores das estâncias de águas, sob o pretexto de que sofrem do estômago ou dos intestinos.

Histeria

A histeria é freqüente no Brasil, principalmente em suas formas convulsivas, observando-se verdadeiras epidemias, como as de astasia-abasia em São Luis do Maranhão em 1879-1881, e na Bahia em 1882 (Nina-Rodrigues ${ }^{2}$ e Alfredo Brito). Mas a história das grandes epidemias de neurose convulsiva mostra que tiveram uma frequiência ainda maior nos países frios da Europa.

2. Trata-se do artigo "A abasia coreiforme epidêmica no Norte do Brasil", de 1890, republicado na Revista Latinoamericana de Psicopatologia Fundamental, São Paulo, ano VI, n. 4, p. 135 44, dezembro de 2003 (N. da R.). 


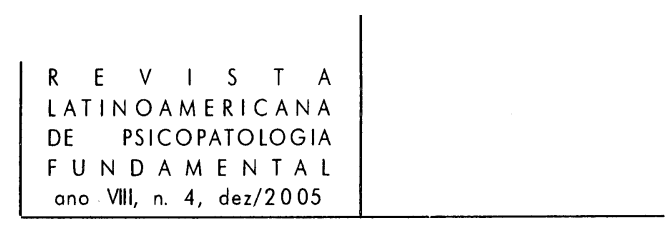

As causas da histeria, em nosso país, não diferem em nada das que agem na Europa e na América do Norte.

\section{Epilepsia}

A proporção desta doença é considerável, principalmente em sua forma convulsiva.

Apesar de encontrarmos freqüentemente todas as variações epilépticas, desde o pequeno mal até as manifestações psíquicas delirantes, e mesmo criminais da neurose (e possuímos quanto a isso casos muito curiosos), observa-se facilmente que o grande ataque é a mais comum das manifestações comiciais. Como causas a assinalar, citaremos o alcoolismo dos pais e a degeneração criada por esta intoxicação e por outras intoxicações mórbidas, alimentares etc.

\section{Degeneração inferior}

Magma confuso de evolução cerebral abortada ou de regressão doentia, sobre a qual se implantam e com a qual se misturam as perversões, os fetichismos, os delírios episódicos. A proporção é considerável, principalmente ao se considerar que, sob esta rubrica, são compreendidos quase todos os casos sem característica precisa e todos aqueles disseminados sob outras rubricas. Como em toda parte, encontra-se nos ascendentes dos doentes o alcoolismo, a sífilis e os abusos venéreos.

\section{Paranóia}

Seguindo as indicações de Kraepelin, excluímos tudo o que a confusão psiquiátrica erroneamente considerou sob esta denominação. Em um trabalho anterior (Moreira e Peixoto, 1905), partilhamos a opinião do professor de Munique. Por encarar a paranóia desta maneira, em 1904 tivemos apenas 1,1\% de casos. Tivemos a sorte de observar em nosso país casos muito instrutivos desta doença.

\section{Alcoolismo}

A porcentagem encontrada por um de nós em um período de dez anos é de $28 \%$, que equivale à anual em nossas estatísticas. O dr. Roxo (1904) observou na Clínica Psiquiátrica da Faculdade do Rio, de 1895 a 1900, 31\% de casos de 


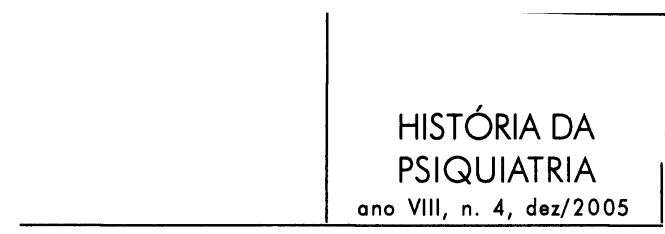

origem alcoólica. Resulta daí que, quanto a este dado, Rio de Janeiro é comparável a Paris e a Viena, ou seja, que a proporção é muito elevada, e ela parecerá ainda mais se for considerada a distância que separa socialmente estas duas grandes capitais da nossa.

\section{Psicoses infecciosas}

Em terrenos preparados pela neuropatia, observa-se um grande número de casos de perturbações mentais que acontecem no período inicial ou no secundário da sífilis, na malária, na varíola, na febre amarela. Encontrando um terreno propício, estas infecções fizeram eclodir as desordens mentais. Não houve erro de imputação nos dois primeiros casos, pois as medicações específicas sempre forneceram uma confirmação positiva.

\section{Confusão aguda}

Entre as psicoses por esgotamento (Das Erschöpfungirresein), Kraepelin reserva a denominação de confusão aguda - Die acute Verwirtheit - (Amentia) - somente para uma categoria dentre os fatos agrupados por Meynert sob o nome de Amentia.

Apesar da raridade desta psicose $(0,5 \%)$, observamos em nosso país casos típicos. Ela é mais freqüente na mulher. As causas mais comuns são os fatores de esgotamento, principalmente o estado puerperal, a exaustão física e as vigílias.

\section{Loucura maníaco-depressiva}

Um de nós (Peixoto, 1905) em dez anos encontrou, entre nossos alienados, 6,6\% de maníaco-depressivos. Ao contrário do que se observa na Europa, onde há excesso de mulheres, observa-se em nosso país uma leve diferença em favor do sexo masculino, que forneceu, em dez anos, 6,8\% contra 6,5\% para o sexo feminino. A loucura maníaco-depressiva é mais tardia entre nós. A comparação de nossos números com os de Kraepelin e de Weignandt mostra que, até os vinte anos, temos muito menos maníaco-depressivos, e após os quarenta anos, temos muito mais do que a Alemanha.

A contribuição dos grupos étnicos é desigual: mais da metade dos casos (53\%) pertencem à assim chamada raça branca; mais de um quarto $(28 \%)$ aos mestiços e mais de um sexto $(19 \%)$ à raça negra (Peixoto, 1905). 


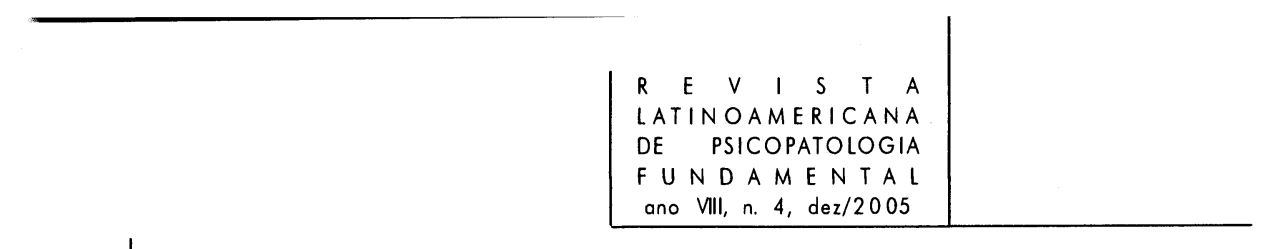

\section{Demência precoce}

A demência precoce, em todas as suas variedades kraepelinianas, é muito freqüente no Brasil: o fato é facilmente observável desde que se agrupou sob esta rubrica casos anteriormente mal classificados.

Os estudos excessivos, que começam com demasiada precocidade no Brasil; maus-tratos domésticos ou nos internatos; os rigores da disciplina; o medo das punições; os perigos de revoluções; estes são com freqüência os fatores ocasionais da doença, verificados entre nós.

Em um total de 1.806 doentes observados no Hospital Nacional de Alienados ao longo do ano de 1904, encontramos 217 dementes precoces, ou seja, $12 \%$, dos quais 165 homens e 52 mulheres, perfazendo uma proporção de $14,5 \%$ para os primeiros e $7,8 \%$ para as segundas. O número total de $12 \%$ é inferior ao de Kraepelin, que indica de 14 a 15\%; inferior igualmente aos de Séglas e Deny que encontram de 13 a 14\%; de J. Crocq, perfazendo 15,66\%; e de Levi Bianchini que chega a $28 \%$; é quase igual ao de Sérieux que encontra de 12 a $16 \%$. A proporção de $10 \%$ dada por Meeus é a menos elevada entre todos os autores.

Nosso número total de $12 \%$ aproxima-se, em suma, bastante daqueles obtidos por Sérieux, Séglas e Deny.

Em Java, o Professor Kraepelin encontrou a demência precoce com muita freqüência. ${ }^{3}$ Infelizmente, ele não fornece a sua proporção.

\section{Involução senil, melancolia de involução, demência senil}

Nos países quentes, assim como nos frios, a velhice não poupa das psicoses. Observamos todas as formas mórbidas descritas na Europa por Ritti, Wille, Kraepelin etc. A proporção destas psicoses senis será certamente menos elevada do que os $8 \%$ estabelecidos em Rhinan por Wille, porque muitos destes doentes são tratados em casa.

\section{Paralisia geral}

Em relação à paralisia geral, dois fatos devem ser observados: um é o menor número de casos entre nós e a extrema raridade desta síndrome nas mulheres, contrariamente ao que se observa em certos países da Europa e em

3. Sobre a viagem de Kraepelin a Java, consultar o livro de Paulo Dalgalarrondo, Civilização e loucura: uma introdução à história da etnopsiquiatria. São Paulo: Lemos, 1996 (N. da R.). 


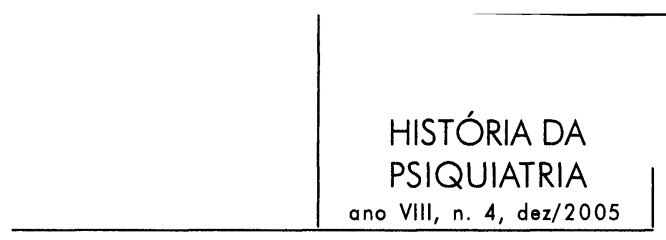

certos Estados da América do Norte; o outro é a progressão crescente, a cada ano, desta afecção no Brasil.

Muñoz e Gustavo Lopez em Cuba, Niven em Bombaim, Plaxton no Ceilão, Manning em New South Wales, Sandwith e Peterson no Cairo, Greenless na África do Sul, Meilhon na Argélia, Holzinger na Abissínia, Ostrowsky na Pérsia, Friedrichsen em Zanzibar, Gillmore Ellis em Cingapura, Bauer, Kok Ankersmit e van Brero nas Índias holandesas, Grieve, Law e Barnes na Guiana Inglesa afirmaram a raridade da paralisia geral nos climas quentes. Van Brero escreveu: "Dementia paralytica ist eine Irrseinsform, welche in tropischen Ländern wenig beobachtet wird". 4

Acreditamos que tanto nos países quentes quanto nos frios a paralisia geral é mais ou menos freqüente conforme o grau de civilização.

No Brasil, ela é mais freqüente nos grandes centros.

Somos informados, pelas estatísticas levantadas por Penafiel e Moreira, ${ }^{5}$ que deram entrada no Hospital Nacional de Alienados no Rio, durante o período de 1889 a 1904, 9.609 doentes e que destes apenas 266, entre os quais 12 mulheres, foram considerados atingidos pela paralisia geral, ou seja, uma proporção de 2,76\% sobre a totalidade das entradas. O Hospital Nacional de Alienados é um hospício público. Na Casa de Saúde do Dr. Eiras, reservada aos doentes das classes mais privilegiadas, a proporção foi de $4,3 \%$. E podemos afirmar que muitos dos doentes são tratados em casa.

Conforme as estatísticas de Franco da Rocha (1904) em São Paulo, a porcentagem nessa cidade é mais elevada: 5,5\%. Em 1.080 homens alienados, encontrou 90 paralíticos, ou seja, 8,3\%. Entre 266 estrangeiros, ele observou 52 paralíticos, ou seja, 8,3\%. ${ }^{6}$ O clima da cidade de São Paulo serve de transição entre o da zona subtropical e o da zona temperada amena. Em conseqüência da altitude, a temperatura dessa localidade diminui consideravelmente e por isso seu clima afasta-se daquele da zona subtropical.

Mas a razão da diferença de porcentagem não é o clima. A imigração estrangeira mais forte explicará o fato.

Apesar de a sífilis atingir uma grande extensão no Brasil, observa-se uma preponderância das formas tegumentares benignas, de modo que o sistema nervoso é relativamente poupado.

4. Em alemão no original: “A dementia paralytica é uma forma de loucura pouco observada em países tropicais” (tradução de Paulo Dalgalarrondo).

5. Em trabalho que seria publicado por Juliano Moreira e Antonio Penafiel, em 1907, no Journal of Mental Science, republicado neste número da RLPF (N. da R.).

6. Possivelmente, um erro tipográfico. Na verdade, 52 paralíticos representam $19,5 \%$ do total de 266 estrangeiros (N. da R.). 
No entanto, ao lado destas manifestações, um de nós observou não apenas numerosos casos de terciarismo ${ }^{7}$ agudo, extenso, que atinge com rapidez os ossos e os tegumentos, principalmente nos doentes dos distritos rurais em que há vários fatores de agravamento da doença, mas ainda casos de terciarismo dos centros nervosos, mais ou menos graves, nos brasileiros descendentes, mais ou menos puros, dos dois grupos étnicos que mais concorreram para o povoamento do país.

Se as localizações encéfalo-medulares de sífilis entre os habitantes do Brasil não são excepcionais, as afecções chamadas de parassifilíticas não são freqüentes, como em certos países da Europa e parecem ser totalmente desconhecidas nos aborígines.

Esta imunidade deve ser atribuída a uma influência étnica? Acreditamos que não. O tipo de vida que levam estes aborígines, cuja atividade é reduzida ao mínimo, é sem dúvida a causa deste estado refratário. Eles não têm as preocupações, os males e o excesso de trabalho intelectual do homem civilizado. Se não conhecem o prazer dos gozos psíquicos, ignoram, em contrapartida, as depressões neurastênicas.

Nos climas tropicais, assim como nos frios, a sífilis é de longe a causa mais freqüente da paralisia geral. Encontramo-la, certa ou provável, em aproximadamente $80 \%$ dos casos. Ela existe como fator predominante em trinta de cem casos.

Qualquer que seja o valor da sífilis como causa da paralisia geral, acreditamos que ela não é a única. Parece suficientemente demonstrado que os tóxicos mais diversos podem dar origem, nas pessoas predispostas, à meningoencefalite difusa.

A estafa por excesso de trabalho, por miséria e principalmente por perversões genésicas, o coito imoderado, os abortos provocados etc., comuns em certas capitais da Europa, são relativamente raros no Brasil. Mas como o quociente do progresso aumenta gradualmente, e como eles os males que o acompanham, a paralisia geral começa a figurar sensivelmente mais freqüente em nosso obituário, e tende a aumentar ainda mais.

Aliás, temos a convicção de que a raridade da demência paralítica nas estatísticas dos principais centros do Brasil é maior do que na realidade. Isto se deve, em sua maioria, aos erros de diagnóstico.

Muitos médicos, e dos mais instruídos, desconhecem a paralisia geral, quando um alienista não hesitaria em atestá-la, e somente a admitem quando a síndrome está completa.

7. Terciarismo: manifestações da fase final da sífilis, que em geral ocorreram vários anos depois da infecção inicial pelo Treponema pallidum (N. da R.). 


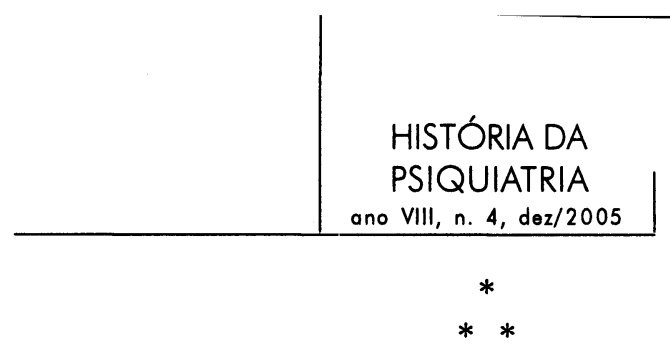

Uma questão que devemos discutir brevemente, antes de concluir, é a da influência dos trópicos sobre o sistema nervoso dos emigrantes dos países frios. Em Manaus, em Belém no Estado do Pará, no do Maranhão, em Fortaleza, em Pernambuco, na Bahia etc., enfim, em toda a região do Brasil considerada como possuindo climas quentes, vimos um grande número de europeus originários dos países do Norte, alemães, noruegueses, russos, ingleses etc., viver nas melhores condições de saúde e conservar um excelente sistema nervoso. É que eles se empenharam em viver conforme o clima e respeitaram as prescrições que aconselha a higiene para a existência em tais condições. Ao lado deles, em contrapartida, vimos muitos cujas perturbações eram devidas aos excessos de cibus, de potus e de vênus. ${ }^{8}$ Um certo número, aliás, devia ter trazido da Europa taras degenerativas que ocasionavam as manifestações mórbidas e, nestes casos, estas últimas teriam certamente aparecido da mesma forma, se os emigrantes não tivessem deixado suas pátrias.

E sem nos deter por enquanto em aprofundar a afirmação, recordaremos que a emigração pode ser o resultado de estados psicopáticos diversos que incitam o homem a se deslocar, seja em virtude de idéias de perseguição ou de grandeza, ou ainda de impulsões relacionadas à histeria, à epilepsia, à paralisia geral etc.

Quanto à insônia persistente de que nos falam Daübler e Rasch, o clima não é de forma alguma sua causa, pois, em nossas zonas equatoriais, não foi observada uma freqüência maior do que na Europa.

Nossas observações estão de acordo com o que afirma o Diretor do Museu do Pará, o estudioso suíço dr. Goeldi (1902), em seu estudo sobre o clima da Amazônia. Ele descreveu: "Nie während eines mehr als 7 jährigen Aufenthaltes habe ich, noch eines meiner Familienmitglieder, noch einer unserer europäischen Museumsangestellten wegen Hitze nicht zu einem erquicklichen Schlafe gelangen können". ${ }^{9}$

Já se observou como particulares aos climas quentes duas síndromes, conhecidas pelos indígenas do Arquipélago Malásio sob os nomes de Latah e de Amok.

8. Ou seja, a excessos alimentares, alcoólicos e sexuais (N. da R.).

9. Em alemão no original: "Nunca, durante uma permanência de mais de sete anos, nem eu, nem um membro de minha família, nem um dos nossos funcionários europeus do Museu pudemos ter, devido ao calor, um sono numa temperatura fresca" (tradução de Paulo Dalgalarrondo). 


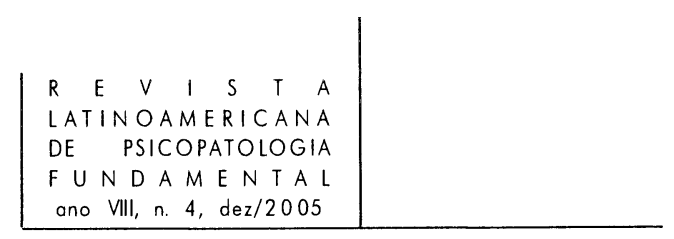

A leitura atenta dos trabalhos de Swaving (apud van Brero), de Vogler (1853, apud van Brero), de van de Burg (apud van Brero), de Rasch (1895), de Gillmore Ellis (1893), de van Brero (1896; 1905) e, finalmente, de Kraepelin (1904; 1904b), que visitou Java no ano passado, leva-nos a crer que o Latah e o Amok não são duas doenças independentes e que não são particulares dos climas quentes. Os fenômenos do Latah (uma miospasmia impulsiva imitativa provocada, segundo Marina e Brero) pertencem certamente, no geral, à doença de Gilles de la Tourette e à histeria. Eles oferecem pontos de semelhança com o miryachit dos siberianos e dos lapões, o jumping dos saltadores norte-americanos e o bah-tschi dos siameses.

O Amok, em contrapartida, não é uma forma mórbida unívoca, mas o nome genérico sob o qual designam-se atos impulsivos extremamente violentos, acompanhados de obnubilação. Na verdade, a maioria desses estados deve ser relacionada à epilepsia.

No ano passado, os jornais do Rio de Janeiro se ocuparam demoradamente com o caso de um indivíduo, que um deles nomeou de Homem-fera. Esse indivíduo, posteriormente internado no Hospital Nacional de Alienados, é um epiléptico: se morasse nas Índias holandesas, seria um típico caso de Amok.

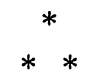

É o momento de dizer algumas palavras sobre os acidentes determinados no homem pelos raios caloríficos do sol. Mas eles não são particulares dos climas tropicais. Nós os temos visto em Berlim e em Paris. São observados sob todas as latitudes, mesmo nos limites setentrionais das regiões temperadas. (Vide Hirsch: Handbuch der historish-geographischen Pathologie 2. ed.; e R. Victor: Allg. Zeits. f. Psych. ${ }^{10} \mathrm{XL}, 1$ e 2.)

Até hoje muito raramente tivemos a ocasião, no Brasil, de observar estas perturbações. Há mais: uma coincidência notável. Um caso de paralisia geral que observamos no hospital, tendo uma insolação nos antecedentes, começou em uma cidade da República do Uruguai, já situada em uma isoterma da zona temperada.

Autores afirmaram que, quando o golpe de calor atinge o sistema nervoso central, ele pode ostentar três formas: a comatosa, a convulsiva e a delirante. Esta última é caracterizada por um delírio agudo. Texier observou um caso em que o doente atingido pelo delírio furioso queria se jogar no mar. Este tipo era anteriormente conhecido sob o nome de calentura ou parafrosina calentura, como o chamava Sauvage. A calentura, diz Fonsagrives, é um delírio febril, súbito,

10. Assim no original. Parece tratar-se de abreviação da conhecida revista alemã Allgemeine Zeitschrifft für Psychiatrie und psychisch-gerichtliche Medizin (N. da R.). 


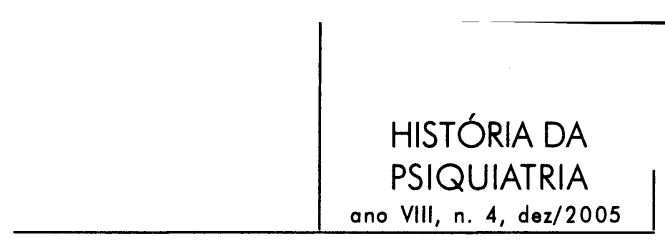

particular dos países quentes, e cujo caráter específico é inspirar no doente o desejo de se jogar ao mar. A existência desta afecção havia se apoiado em alguns fatos, entre os quais o mais importante é a história, relatada por Gaulthier, de trinta marujos e do médico de bordo se jogando ao mar em um acesso de delírio furioso (apud Bondin, Géographie et stat. médicales). Acreditamos que esta modalidade mórbida torna-se rara graças, sobretudo, aos progressos da higiene dos navios, porque por diversas vezes atravessamos o Equador e não observamos um único caso.

Há muito tempo, aliás, Fonsagrives dizia não haver encontrado um único exemplo, durante quatro anos de navegação nas costas da África, em um efetivo de 3.000 homens. Em terra, diz-se, o golpe de calor delirante pode acometer com a mesma intensidade. Repetimos que esta forma mórbida não é particular aos climas quentes porque, segundo Pringle, é durante os maiores calores na Holanda que se observaram no exército inglês estas febres, assinaladas em seu início por um frenesi súbito e tão violento que os soldados se lançavam de seus carros nos pântanos que bordejavam a estrada.

$\mathrm{O}$ que quer que signifique a patogenia do golpe de calor, o aparecimento de seus acidentes cerebrais é favorecido por predisposições individuais. A influência do alcoolismo profissional ou do abuso acidental de bebidas alcoólicas é evidente. Kelsch insistiu com muita razão sobre a vulnerabilidade especial dos sujeitos portadores de taras orgânicas, de insuficiência funcional do rim e principalmente de disposições mórbidas, inatas ou adquiridas, do músculo cardíaco.

O professor Le Dantec (1905, p. 180) escreveu: "Os fortes calores acompanhados de noite por insônia, a ausência de qualquer distração, criam nas colônias um estado mental particular que se chamou pelo nome característico de sudanita, porque é observado com máxima intensidade no Sudão. As outras colônias não estão imunes a isto etc."

Nas zonas mais quentes do Brasil não observamos absolutamente nada de semelhante à conhecida sudanita. Aliás, estamos convencidos de que as vítimas desta psicopatia pseudotropical são degenerados comuns que facilmente começam a delirar, principalmente por causa da maneira viciada de viver nos climas quentes. É preciso sanear as cidades: nelas quase todos se dedicam a perder a saúde. A estafa, o alcoolismo, o relaxamento mais ou menos disfarçado dos costumes, tudo isso forma candidatos ao fracasso moral e intelectual.

Assim dizia o professor George Treille, desde 1899: "Nos países quentes assim como na zona temperada, é menos do lado dos meteoros do que das deficiências da higiene individual e social, menos nos transtornos funcionais causados pelo clima na fisiologia do homem do que nas aberrações do regime de vida que é preciso procurar as causas da alteração da saúde do europeu". 


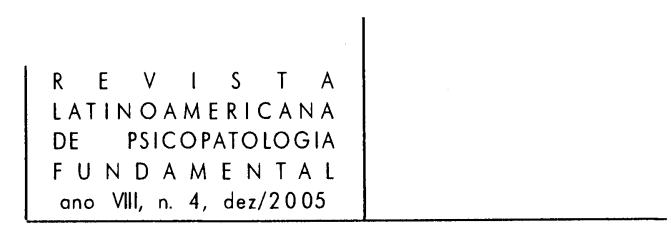

Há uma questão ligada a esta dos climas, que é a influência dos grupos étnicos sobre a produção e a freqüência das psicoses. Para evitar prolongar este trabalho, não publicaremos agora os resultados de nossas pesquisas. Em relação a esta questão, acreditamos que há um número de preconceitos a destruir. Nós a discutiremos em um trabalho posterior.

\section{Conclusões}

1. Não existe, nas zonas climáticas chamadas tropicais, nem nos nativos do país, nem nos europeus, nenhuma forma patológica estranha à neuropsiquiatria de outros climas.

2. Não existe nenhuma relação entre a proporção dos casos de loucura acontecidos no Rio e nas outras cidades do Brasil, e as máximas térmicas das mesmas cidades.

3. Não existe nenhuma correlação entre os componentes climáticos (temperatura, estado higrométrico etc.) e o número de casos de loucura, nas regiões quentes do Brasil.

4. Nos climas quentes, as correlações das influências meteorológicas e das estações sobre os alienados apresentam, assim como nos climas frios, diferenças individuais. Não poderiam se formuladas regras gerais a este respeito.

5. A influência dos trópicos sobre o sistema nervoso dos indivíduos originários de países frios varia muito de indivíduo para indivíduo, mas na maioria das vezes ela está ligada à maneira de viver de cada um e à organização de seu sistema nervoso.

6. Não há motivos para crer que nos climas tropicais haja uma maior freqüência de psicoses ligadas à malária. Seu aparecimento nos indivíduos atingidos pelo impaludismo depende de outros fatores.

7. O clima não influi em nada sobre os sintomas das diversas psicoses. É no grau de instrução do indivíduo que reside a causa das diferenças que podem se apresentar. $\mathrm{O}$ descendente puro de dois caucasianos, igualmente puros, criado no interior, no meio de pessoas ignorantes, apresenta os mesmos delírios rudimentares que os indivíduos de cor desprovidos de instrução. 


\section{HISTÓRIA DA}

PSIQUIATRIA

ano VIII, n. 4, dez/2005

\begin{tabular}{|c|c|c|c|c|c|c|}
\hline \multicolumn{7}{|c|}{$\begin{array}{l}\text { TABELA } \\
\text { Proporção das síndromes mentais observadas em } 1.806 \text { admissões no } \\
\text { Hospital Nacional de Alienados e na Colônia de Alienados do Rio, em } 1904\end{array}$} \\
\hline & \multicolumn{2}{|c|}{$\begin{array}{l}\text { Em } 670 \\
\text { mulheres }\end{array}$} & \multicolumn{2}{|c|}{$\begin{array}{c}\text { Em } 1.136 \\
\text { homens }\end{array}$} & \multicolumn{2}{|c|}{$\begin{array}{c}\text { Em } 1.806 \\
\text { admissões }\end{array}$} \\
\hline & $\begin{array}{l}\text { Ne de } \\
\text { casos }\end{array}$ & $\%$ & $\begin{array}{l}\text { Ne de } \\
\text { casos }\end{array}$ & $\%$ & $\begin{array}{l}\text { Ne de } \\
\text { casos }\end{array}$ & $\%$ \\
\hline Idiotia & 10 & $(1,4 \%)$ & 28 & $(2,4 \%)$ & 38 & $(2,1 \%)$ \\
\hline Imbecilidade & 19 & $(2,8 \%)$ & 81 & $(7,1 \%)$ & 100 & $(5,5 \%)$ \\
\hline Debilidade mental & 11 & $(1,6 \%)$ & 35 & $(3,0 \%)$ & 46 & $(2,5 \%)$ \\
\hline Neurastenia & - & - & 4 & $(0,4 \%)$ & 4 & $(0,2 \%)$ \\
\hline Histeria & 186 & $(27,7 \%)$ & 9 & $(0,8 \%)$ & 195 & $(10,8 \%)$ \\
\hline Epilepsia & 72 & $(10,7 \%)$ & 121 & $(10,6 \%)$ & 193 & $(10,8 \%)$ \\
\hline $\begin{array}{l}\text { Estados psicopáticos: } \\
\text { degeneração }\end{array}$ & 10 & $(1,4 \%)$ & 66 & $(5,8 \%)$ & 76 & $(4,2 \%)$ \\
\hline Paranóia & 4 & $(0,6 \%)$ & 16 & $(1,4 \%)$ & 20 & $(1,1 \%)$ \\
\hline Psicose tóxica: alcoolismo & 103 & $(15,3 \%)$ & 328 & $(28,8 \%)$ & 431 & $(23,9 \%)$ \\
\hline Psicose autotóxica: puerperal & 2 & $(0,3 \%)$ & - & - & 2 & $(0,1 \%)$ \\
\hline Psicose autotóxica: de esgotamento & 8 & $(1,2 \%)$ & 3 & $(0,3 \%)$ & 11 & $(0,6 \%)$ \\
\hline Psicose infecciosa: sífilis & - & - & 17 & $(1,5 \%)$ & 17 & $(0,9 \%)$ \\
\hline Psicose infecciosa: variola & - & - & 1 & $(0,1 \%)$ & 1 & $(10,8 \%)$ \\
\hline Psicose infecciosa: beribéri & - & - & 1 & $(0,1 \%)$ & 1 & $(0,05 \%)$ \\
\hline Psicose infecciosa: malária & - & - & 3 & $(0,3 \%)$ & 3 & $(0,15 \%)$ \\
\hline Psicose infecciosa: febre amarela & 1 & $(0,1 \%)$ & - & - & 1 & $(0,05 \%)$ \\
\hline Psicose infecciosa: anônima (atípica) & 5 & $(0,7 \%)$ & 22 & $(2,0 \%)$ & 27 & $(1,5 \%)$ \\
\hline Loucura maníaco-depressiva & 90 & $(13,3 \%)$ & 89 & $(7,9 \%)$ & 179 & $(9,9 \%)$ \\
\hline Paralisia geral & 1 & $(0,1 \%)$ & 44 & $(3,9 \%)$ & 45 & $(2,4 \%)$ \\
\hline Demência precoce & 52 & $(7,8 \%)$ & 165 & $(14,5 \%)$ & 217 & $(12,0 \%)$ \\
\hline Demência terminal consecutiva & & & & & & \\
\hline a diversas psicopatias & 64 & $(9,5 \%)$ & 53 & $(4,7 \%)$ & 117 & $(6,5 \%)$ \\
\hline Involução senil paranóide & - & - & 2 & $(0,2 \%)$ & 2 & $(0,1 \%)$ \\
\hline Melancolia de involução & - & - & 7 & $(0,6 \%)$ & 7 & $(0,3 \%)$ \\
\hline Demência senil & 20 & $(2,9 \%)$ & 11 & $(1,0 \%)$ & 31 & $(1,7 \%)$ \\
\hline Não-alienados & 2 & $(0,3 \%)$ & 15 & $(1,3 \%)$ & 17 & $(0,9 \%)$ \\
\hline Em observação & 10 & $(1,4 \%)$ & 15 & $(1,3 \%)$ & 25 & $(1,4 \%)$ \\
\hline TOTAL & 670 & $(100 \%)$ & 1.136 & $(100 \%)$ & 1.806 & $(100 \%)$ \\
\hline
\end{tabular}




\section{Referências}

Barnes, W. S. Notes on the insanity of British Guiana. Guiana Medical Annual, p. $90,1891$.

BiNET. Recherches au sujet de l'influence des conditions météorologiques sur les aliénés. Tese. Paris, 1873.

EluIs, G. The amok of the Malays. Journal of Mental Science, v. 39, p. 325-38, jul./1893.

Esquirol, J. E. Des maladies mentales considérées sous les rapports médical, hygiénique et médico-légal. Paris, 1838. v. I.

Franco Da Rocha, F. Estatísticas e apontamentos sobre o Hospício de São Paulo 18951903. In: Esboço de psychiatria forense, 1904.

GoELDI, E. Zum Klima von Pará. Separatabdruck v. Meteoreloszeitschrift, 1902.

Greenless, D. A contribution to the statistics of insanity in Cape Colony. American. Journal of Insanity, p. 519, abr./1894.

Insanity among the natives of South Africa. Journal of Mental Science, v. 41, p. $71-78$, jan./1895.

GRIEve, R. Insanity in British Guiana. Journal of Mental Science, v. 26, p. 370-4, 188081.

GuisLain, J. Leçons orales sur les phrénopathies. 2. ed. Paris, 1880. v. I, p. 451.

HoLtsingER, F. Dushevntya boliezni v. Abisinii (Maladies mentales em Abyssinie). Oboz. r. psichiat. nevrol. São Petersburgo, II, p.161-170 (e S. Petersb. med. Wochenschrift, n. F 14, Beil 47, 1897).

Kraepelin, E. Vergleichende Psychiatrie. Centralblatt für Nervenheilhunde und Psychiatrie, 15, p. 433-7, jul./1904.

Psychiatrisches aus Java. Allgemeine Zeitschrift für Psychiatrie und psychischgerichtliche Medizin, 61, p. 882-4, 1904b.

Law, W. F. Insanity in British Guiana. Georgetown Hospital Reports, p. 19, 1888.

Le Dantec, A. Pathologie exotique. 2. ed. 1905. p. 180.

Lombroso, $\mathrm{C}$. De l'influence des phénomènes atmosphériques et de la lune sur les aliénés. Annales médico-psychologiques, v. 10, p. 563, 1867 e v. 12, p. 152, 1868.

LóPEZ, G. Notas sobre las afecciones mentales más frecuentes en Cuba. Crónica Médico-Quirúrgica de la Habana, p. 105 e p. 150, 1891.

Manning. Chinese lunatics. Journal of Mental Science, v. 21, p. 81, 1875-76. $1879-80$

Statistic of insanity in Australia. Journal of Mental Science, v. 30, p. 165-77,

MeiLhon. L'aliénation mentale chez les Árabes. Annales médico-psychologiques, v. 3, p. $17-32 ;$ p. $177-207$ e p. 364-77, 1896. 


$\mid$\begin{tabular}{c} 
HISTÓRIA DA \\
PSIQUIATRIA \\
ano VIII, n. 4, dez/2005 \\
\hline
\end{tabular}

Moreira, J.; Peixoto, A. A paranóia e os síndromas paranóides. Archivos Brasileiros de Psychiatria, Neurologia e Sciencias Affins, Rio de Janeiro, v. 1, n. 1, p. 5-33, 1905. [Revista Latinoamericana de Psicopatologia Fundamental, São Paulo, ano IV, n. 2, p. 134-67, jun./2001].

Moreira, J.; Penafiel, A. A contribution to the study of dementia paralytica in Brazil. Journal of Mental Science, v. 53, p. 507-21, 1907.

MuÑoz. Quelques mots sur la demence paralytique observée à l'île de Cuba. Annales médico-psychologiques, p. 188, 1866.

Ostrowsky. Über die nervöse und psychische Erkrankung in Persien. Ref. Neurologiches Centralblatt, n. 8, p. 381, 1899.

Peixoto, A. Loucura maníaca-depressiva. Archivos Brasileiros de Psychiatria, Neurologia e Sciências Affins, Rio de Janeiro, v. 1, n. 1, p. 33-52, 1905. [Folie maniaque depressive. Annales médico-psychologiques, março e abril de 1905].

Penafiel, A. Paralysia geral dos alienados no Brasil. Tese. Rio de Janeiro, 1904.

Peterson. The insane in Egypte. Medical Record, maio/1892.

RASCH. Über die Amok Krankheit. Neurologisches Centralblatt, n. 19, 1895.

RASCH. Krankheiten in Königreich Siam. Virchow's Arch., v. 140, s/d.

Roxo, H. Causas de alienação mental no Brasil. Brasil-Medico, Rio de Janeiro, p. 31, 1904.

VAN BRERo, P. C. Einiges über die Geisteskrankheiten de Bevölkerung des malaüschen Archipels. Allgemeine Zeitschrift für Psychiatrie und psychisch-gerichtliche Medizin, v. 35 , p. $15,1896$.

Jets over Latah. In: Geneeskundig Tijdscrift voor Nederlandsch Indie Deel. XXXII A fl. 5 (?), s/d.

Die Nerven und Geisteskrankheiten in den Tropen. In: Mense, C. (ed.). Handbuch der Tropenkrankheiten, 1905. 